\title{
A miséria na literatura: José do Patrocínio e a seca de 1878 no Ceará*
}

Frederico de Castro Neves ${ }^{* *}$

Este artigo busca compreender a construção de um olhar intelectualizado sobre os eventos que marcaram a grande seca de 1877-1880, no Ceará. A partir dos escritos de José do Patrocínio, podemos avaliar o impacto simbólico que a miséria dos retirantes causou nas mentes cultas do final do Império, ao expressarem uma visão moralizante sobre a desagregação das famílias sertanejas, construindo a seca como um momento de ruptura da ordem senhorial, base de constituição da nação brasileira.

Palavras-chave: Literatura - Retirantes - Seca

Poverty and Literature: José do Patrocínio and the drought of 1878in Ceará This article seeks to understand the construction of an intellectual view about the tragic events witch took place during the Great Drought of 1877-1880 in Ceará. We can evaluate, throught José do Patrocínio's writings, the symbolic impact that the refugees' misery caused in the Brazilian intelligentzia in the final years of the Empire. His chronicles expressed a moral view on the desegregation of the families and joined many writers and intellectuals that were thinking the drought as a social disruption, seen as the moral basis of the Brazilian nation.

Keywords: Literature - Refugees - Drought

\footnotetext{
*Artigo recebido em outubro de 2006 e aprovado para publicação em dezembro de 2006.

** Professor do Departamento de História da Universidade Federal do Ceará. Pesquisa desenvolvida com o apoio do MCT/CNPq. E-mail: fredeneves@msn.com.
} 


\section{La Misère dans la Littérature: José do Patrocínio et la sècheresse de 1878 au Ceará}

Cet article cherche à comprendre la construction d'un regard intellectualisé sur les évènements tragiques ayant marqué la grande sécheresse de 1877-1880 au Ceará. A partir des écrits de José do Patrocinio, nous pouvons évaluer l'ampleur de l'impact symbolique que la misère des émigrés (retirantes) a causé sur les esprits cultivés de la fin de l'Empire. Les chroniques de José do Patrocinio expriment une vision moralisatrice de la désagrégation des familles du sertão et approchent la sécheresse comme un moment de rupture de l'ordre seigneurial, considéré comme étant la base de la nation brésilienne.

Mots-clés: Littérature - Retirantes - Sécheresse

Em 1877, quando passou a escrever no jornal carioca Gazeta de Notícias, José do Patrocínio (1854-1905) ainda não se havia tornado o inflamado jornalista que agitou a cena política do Rio de Janeiro, nos anos finais da escravidão e da monarquia. Suas atividades como abolicionista iriam tomar grande impulso somente depois de 1880, quando, em meio a uma variedade de eventos, participa da fundação da Sociedade Brasileira contra a Escravidão, juntamente com Joaquim Nabuco e outros. Desde então, o abolicionismo passou a centralizar todas as suas preocupações políticas e sociais, deixando para segundo plano suas preferências republicanas ou liberais. A luta pela abolição dos escravos, segundo ele, ultrapassava os muros da política partidária, arrebatando suas energias e seu "temperamento apaixonado e explosivo".

Como correspondente do Gazeta de Notícias, visita o Ceará entre maio e setembro de 1878, com a missão de enviar à Corte informações qualificadas sobre a seca que, então, assolava aquela província. Era um momento extremamente delicado. Não se sabe ao certo que espécie de informações ele possuía previamente sobre o Ceará ou sobre a seca, a não ser que a mortalidade entre a população local era muito alta e que as doenças se haviam propagado de forma impressionante. Só se sabia que uma tragédia sem precedentes estava em curso; e algumas lições haveriam de ser aprendidas por todos.

Com certeza, ele sabia que, premidos pela destruição das colheitas, os camponeses pobres das áreas centrais da província abandonavam suas terras e dirigiam-se para os centros urbanos, em busca de auxílio. A situação nos

\footnotetext{
${ }^{1}$ José Murilo de Carvalho, "Com o coração nos lábios", disponível em http://omnis.if.ufrj. br/ coelho/campanha_abolicionista. html (Acessado em 04.09.2001).
} 
campos abandonados, nas estradas e nas cidades, principalmente Fortaleza, onde a população quintuplicou em menos de um ano, era a pior possível. ${ }^{2}$ Os jornais da Corte (Jornal do Commercio e Gazeta de Notícias, principalmente), além dos locais (Cearense e D. Pedro II, os maiores, mas também O Retirante, O Echo do Povo e O Colossal, pequenos jornais oposicionistas ou "populares"), desde os primeiros sinais da tragédia, por volta de maio de 1877 , noticiavam os acontecimentos mais impactantes, sob as rubricas de "secca do Ceará" ou "secca do Norte". Em 1878, os editoriais passaram a abordar sistematicamente a questão, analisando as possibilidades de assistência, a ação do Estado e as possíveis soluções definitivas para o problema.

Os retirantes espalhavam-se não só pelas cidades das províncias afetadas (especialmente Ceará e Pernambuco, além de Paraíba e Bahia), mas também se deslocavam (ou eram deslocados) para lugares distantes, como Belém ou Rio de Janeiro. Suas súplicas, assim como seus pontos de vista tradicionais sobre a caridade, o trabalho e a mendicância, passaram a fazer parte da reflexão letrada em praticamente todo o território nacional. As soluções encontradas ou a serem descobertas igualmente se tornaram temas recorrentes nos debates parlamentares e científicos em diversas instituições do país, como o Instituto Politécnico do Rio de Janeiro.

Nos jornais, predominava um tom de sensacionalismo, com o noticiário de misérias e acontecimentos bizarros envolvendo seres extenuados pelo delírio da fome; no Instituto Politécnico, contudo, o estimulante ambiente de debate científico atraía vários intelectuais, de diversas correntes políticas. As propostas direcionavam-se ora para o atendimento imediato, por meio da abertura de uma rede de transportes capaz de levar o auxílio até os locais de moradias dos camponeses mais afetados, ora para a preocupação com um plano de longo prazo, que pudesse minorar os efeitos da calamidade e alicerçar uma produção econômica menos vulnerável às variações do clima. Homens como André Rebouças e Gustavo Capanema, assim como Beaupaire Rohan, Viriato de Medeiros, Castro Carreira e tantos outros, eventualmente com o estímulo direto do Imperador D. Pedro II ou do Conde d'Eu, dedicavam boa parte de seu tempo a buscar soluções "científicas" para a tragédia que se desenrolava diante dos olhos despreparados e surpreendidos das principais lideranças políticas e intelectuais do país.

${ }^{2}$ Cf. Rodolpho Theophilo, História da Secca do Ceará (1877-1880), Rio de Janeiro, Imprensa Inglesa, 1922; Frederico de Castro Neves, “A 'Capital de um Pavoroso Reino': Fortaleza e a seca de 1877”, Tempo, Niterói, v. 5, nº 9, 2000, p. 93-111. 
Por quase todas as províncias, ao mesmo tempo, expandiu-se uma rede de solidariedade que se organizava a partir de inúmeras "comissões de soccorros", formadas por pessoas caridosas, cearenses ou não, que recolhiam alimentos e dinheiro, enviando os valores apurados ao Presidente da Província do Ceará, para que fossem distribuídos entre os pobres. Na Corte, o médico Liberato de Castro Carreira liderou uma grande campanha de arrecadação de donativos e, como tesoureiro da "comissão de soccorros" local, prestou contas nos jornais do dinheiro enviado à sua terra natal; ao mesmo tempo, denunciou os obstáculos que enfrentou para desempenhar sua caridosa missão e ainda escreveu artigos sobre as medidas a serem implementadas para atenuar os efeitos da seca. Evitando soluções que pudessem alterar as estruturas econômicas e políticas da sociedade sertaneja, defendia a construção imediata de estradas, das cidades litorâneas ao interior da província, permitindo a rápida chegada do auxílio aos pobres, em tempo de calamidade natural, impedindo as migrações e a desestruturação das propriedades. Neste sentido, combatia a tendência predominante entre alguns liberais, que pretendiam interferir profundamente nas estruturas produtivas do sertão, seja por meio da construção de diversos açudes públicos, como propunha o Conselheiro Rohan, seja por meio da colonização de áreas férteis disponíveis, como defendia André Rebouças. Juntamente com Viriato de Medeiros, Castro Carreira lutava por uma intervenção rápida na região, por intermédio da criação de obras públicas e frentes de trabalho que incorporassem imediatamente a mão-de-obra dos camponeses deslocados de suas terras, transformando-os em trabalhadores "produtivos", neutralizando seu potencial de revolta e, ao mesmo tempo, dotando a província de equipamentos urbanos e rurais que lhe permitiriam inserir-se no civilizado mundo moderno. ${ }^{3}$

Todo este clima era certamente acompanhado por José do Patrocínio. Em artigo intitulado "Sermão de lágrimas", publicado no semanário O Besouro, o jornalista já indicava, antes mesmo da viagem, as suas principais preocupações com relação à seca e a seus efeitos. Falando sobre os retirantes que eram recebidos em hospedarias improvisadas no Rio de Janeiro, destaca "a profanação dos mais castos sentimentos conjugaes" e as "scenas de lamentosa anormalidade desdobradas pelos caminhos na promiscuidade extenuadora do infortúnio". Enfatiza "a virgindade soffrendo em seu pudor", as "grinaldas vendidas por um punhado de farinha" e a "maternidade sacrificada nos seus

${ }^{3}$ Cf. Tyrone A. P. Cândido, Trem da Seca: sertanejos, retirantes e operários (1877-1880), Fortaleza, Museu do Ceará, 2005, p. 22-39. 
mais santos devotamentos". O que chama a sua atenção, portanto, mais do que a fome e a miséria das famílias retirantes, mais do que a vulnerabilidade social dos sertanejos, é a degradação dos costumes tradicionais e dos valores morais que, segundo ele, deveriam ser o esteio da própria nacionalidade recentemente constituída e agora ameaçada pela desgraça natural. As causas desta decadência pareciam ser "o abandono da terra natal e a emigração para outros climas, outros costumes, outra educação", conseqüências da seca, que deslocava todos de seus lugares de origem. Os retirantes não só deixavam para trás seu torrão conhecido, mas especialmente largavam seus "costumes simples", sendo "inopinadamente arremessados em uma capital, que absorveu já todos os vícios do mundo". O choque cultural provocaria, segundo o jornalista, a desagregação dos valores tão solidamente estruturados na sociedade "simples" em que viviam, onde as relações sociais "a que estão habituados" se baseiam na "confiança plena" que dispensam uns aos outros. ${ }^{4} \mathrm{O}$ contraste entre o mundo rural tradicional, organizado a partir de relações pessoais de reciprocidade e dependência, e o mundo urbano moderno, cuja "liberdade individual" transforma a sociedade em uma guerra de todos contra todos, parece, portanto, direcionar a reflexão de Patrocínio, em sua busca por entender a calamidade e seus efeitos na ordem moral.

Há, em seus escritos desse momento, duas linhas de raciocínio que se combinam, mas não se confundem: 1 . os problemas gerados na estrutura social por um fenômeno climático de intensa gravidade; 2. o aviltamento moral próprio do processo de urbanização. Ao retirar-se do campo, o homem pobre do sertão cearense não somente se desliga de um mundo conhecido e estável, como também se insere em um universo de mentiras, mudanças, velocidade e enganos, característico das cidades grandes, que já absorveram "todos os vícios do mundo". José do Patrocínio, assim, articula uma dupla crítica ao processo de crise por que passavam o Império e seus valores morais: de um lado, o processo de urbanização, possibilitando a emergência de novos sujeitos que questionam os suportes ideológicos da monarquia, parece desagregar valores solidamente interiorizados na sociedade brasileira de origem agrária; de outro lado, as idéias liberais, praticadas contraditoriamente pelos políticos que se

\footnotetext{
${ }^{4}$ O Besouro, Rio de Janeiro, 04.05.1878, p. 37-38. Apesar de todas essas narrativas impactantes, os colegas de Patrocínio ironizavam sua viagem, desejando, em carta pública, que ele não tenha "morrido á fome e menos de béri-béri - cousas essas com que muita gente não se tem dado bem por ahi” (25.05.1878, p. 58). Este hebdomadário, originalmente humorístico e satírico, pede licença a seus leitores para falar da seca e "abre um parenthesis aos seus zumbidos alegres, a sua jovialidade innata, para pedir um pouco de attenção para semelhante facto”.
} 
assenhoreiam do governo durante a década de 1870, à revelia do Imperador, mostram-se incapazes de enfrentar uma tragédia de proporções gigantescas como a que se desenhava na Província do Ceará - desprezando os mecanismos tradicionais de atendimento às carências da população pobre em tempos de escassez, as autoridades não dispõem de meios para o atendimento emergencial ao povo, abandonando o disposto na Constituição imperial de 1824 em nome dos princípios liberais de livre comércio. Para Patrocínio, "o socorro em tempo de calamidade é lei, logo o Estado ao dal-o cumpre apenas com um dever", deslocando os sentidos da ação estatal em relação aos pobres; assim como o engenheiro André Rebouças, que, um ano antes, afirmara que "o governo imperial não pode deixar morrer uma só pessoa de fome sem faltar ao primeiro de seus deveres". O liberalismo defendido pelos dois afamados abolicionistas devia adaptar-se aos momentos de crise e escassez extrema, como era o caso, e exigir do Estado uma posição firme em defesa de costumes estabelecidos de proteção aos pobres, mesmo que sejam costumes de controle sobre o mercado de trabalho ou de alimentos, baseados nas necessidades diretas dos camponeses pobres. ${ }^{5}$ Nestes momentos, valia a pena retornar aos conhecidos mecanismos tradicionais de proteção aos necessitados, com referências relativas à caridade cristã e às trocas desiguais do paternalismo. Todavia, não se tratava mais de um "favor" pessoal, mas de um "dever" do Estado. Isto porque, entre outras coisas, a calamidade que se apresentava naquele momento não se assemelhava a um

${ }^{5}$ Gazeta de Notícias, Rio de Janeiro, 12.09.1878; Jornal do Commercio, Rio de Janeiro, 14.10.1877. O texto de 1824, sucintamente, estabelecia apenas que "a Constituição também garante os socorros públicos" (art. 179, item XXXI) - o que possibilita um leque bastante amplo de interpretações, muitas delas contraditórias. $\mathrm{O}$ mecanismo tradicional de assistência às calamidades era a caridade praticada pelo Estado (centralizando na figura do Imperador todo um imaginário de proteção) e pelos particulares, através da distribuição de víveres e dinheiro com verbas oriundas da rubrica orçamentária "Soccorros Públicos", aplicável apenas em situações de calamidades. No entanto, o Decreto $\mathrm{n}^{\circ} 2.884$, de $1^{\circ}$ de fevereiro de 1862 , já preconizava que os socorros deveriam ser prestados em auxílios diretos (medicamentos, roupas, gêneros alimentícios) e nunca em dinheiro. Um debate intenso se desenrolou durante os anos da seca, entre os intelectuais do Império, sobre o papel do Estado em momentos de crise e/ou calamidade pública e sobre as medidas a serem empregadas para dar suporte à população em perigo. Cf. Frederico de Castro Neves, “Desbriamento' e 'Perversão': olhares ilustrados sobre a seca de 1877", Projeto História, São Paulo, n² 27, 2003, p. 167-189; Ronaldo Pereira, "O povo e o Imperador: classes populares e imagem da Monarquia na corte e na capital da República", LOCUS: revista de história, Juiz de Fora, v. 4, n² 2, 1998, p. 95-108. Nos períodos anteriores a 1877 , as dificuldades eram prioritariamente resolvidas no interior das próprias fazendas, na concessão de favores pelos fazendeiros - permissão para uso de currais abandonados ou cessão temporária de terras férteis - e na ação caridosa de suas esposas - distribuição de donativos e remédios. Cf. A. Otaviano Vieira Jr., Entre paredes e bacamartes. História da família no sertão (1780-1850), São Paulo, Hucitec; Fortaleza, Edições Demócrito Rocha, 2004, p. 23-50. 
acidente que tornava os trabalhadores inválidos para o trabalho "e, portanto, no caso de auxilio do Estado"; mas, ao contrário, "são homens sadios, que, atirados á indigência pelo aniquilamento de suas lavouras, se entregarão ao trabalho desde que sejam alimentados" - daí por que as vítimas da seca "estão em condições inteiramente excepcionaes". ${ }^{6}$ Ao mesmo tempo, são trabalhadores tradicionais, cujas características eram freqüentemente criticadas pelos intelectuais progressistas do Império, levados ao "ócio" pelas circunstâncias da seca e do sistema de esmolas. Até mesmo o conservador Castro Carreira, um ano depois, apesar de reafirmar que "a Constituição manda dar esmolas e não obriga ao trabalho", concorda que ela "não podia cogitar senão de uma calamidade transitoria, de uma peste, de uma inundação", e conclui que "ninguém certamente acreditará, que tendo o governo de sustentar 100,000 ou 200,000 pessoas, seja mais útil conservar na ociosidade e na indolência esta população, do que occupa-la no trabalho". Tratava-se realmente de uma situação excepcional. ${ }^{7}$

As dimensões da tragédia e sua excepcionalidade acentuavam a crise dos mecanismos tradicionais de relação entre o Estado e a pobreza, levando a uma situação em que os novos elementos e interpretações propostas pelos liberais não haviam ainda sido "testados" em conjunturas concretas. O retorno a práticas tradicionais do mundo rural, portanto, parecia uma alternativa viável, que reproduzia certas imagens da natureza como fonte de uma sabedoria singela e eficaz, baseada no costume imemorial dos antepassados e em uma relação saudável com o meio ambiente.

Em contraste com o mundo urbano em expansão, onde se desenvolvem comportamentos tipicamente arrivistas, pouco aceitáveis do ponto de vista da moral aristocrática tradicional, o campo parecia conter os elementos que poderiam garantir a construção e a permanência de uma sociedade civilizada,

\footnotetext{
${ }^{6}$ Rodolpho Theophilo, História da Secca do Ceará (1877-1880), op. cit., p. 356.

${ }^{7}$ Jornal do Commercio, Rio de Janeiro, 04.07.1879. Em editorial intitulado "A colonisação nacional" (09.01.1878), o Jornal do Commercio procura "expender algumas considerações acerca da necessidade de fixarem-se novos destinos á parte, não pouco importante, da nossa população, que vive em condições de quasi nomades, e constitue um elemento negativo da prosperidade e progresso nacionaes" - os "aggregados". Publicado em meio a inúmeras matérias sobre a seca e seus problemas, este texto, a cada linha, aproxima mais a definição de "aggregado" à de "retirante", igualmente um camponês sem posses, sem ambição, alheio às conquistas da modernidade etc. Para este mesmo jornal (02.07.1877), "o systema de soccorros por esmolas é o mais prejudicial e pernicioso que se póde imaginar”. Para André Rebouças, "a esmola avilta". André Rebouças, A Sêcca nas Províncias do Norte, Rio de Janeiro, Typ. de G. Leuzinger \& Filhos, 1877, p. 43.
} 
mas, ao mesmo tempo, ancorada em valores morais estabelecidos a partir da tradição senhorial.

Nesta visão idealizada do mundo rural, parece estar presente a obra de José de Alencar (1829-1877), O Sertanejo, publicada três anos antes. ${ }^{8}$ Neste romance, a vida no campo caracteriza-se pela lealdade (dos pobres) e pela proteção (dos ricos), marcas de um paternalismo que iria garantir a estabilidade desta sociedade tradicional, cujos conflitos aparecem como rixas pessoais entre vaqueiros ou grandes proprietários, em que está em jogo, invariavelmente, a defesa da honra pessoal ou familiar. A definição do "tipo nacional", a que se propunha Alencar, passa primeiramente pela configuração racial: o sertanejo é um mestiço que incorpora as características dos brancos (a valorização da família e da honra pessoal) e dos índios (a lealdade, a obediência, a força física e moral). As relações sociais, resultado da conquista pelos portugueses de uma área inóspita e habitada apenas por índios bravios, são marcadas pela reciprocidade desigual de grupos sociais que conhecem seus lugares no interior de uma hierarquia rígida e natural, que, ao mesmo tempo, garante a sobrevivência de todos e fornece sólidas referências identitárias.

Escrito no contexto de abundância e de crescimento econômico gerado pela súbita expansão da cultura do algodão, especialmente durante a Guerra Civil nos EUA (1871-1875), ao longo de um período de regularidade climática quase sem precedentes (1845-1877) na província, O Sertanejo expressa um ponto de vista que pode ser associado ao que se costuma chamar de "mentalidade senhorial", com sua estreita vinculação ao regime de propriedade da terra, ao controle pessoal da mão-de-obra, à valorização da obediência e da lealdade e à construção de um conjunto de relações sociais marcadas pelo mandonismo, pela afetividade e pela violência. A sensação de uma riqueza duradoura e segura, produzida sob a direção de uma camada de proprietários herdeiros diretos dos colonizadores brancos, parecia configurar a percepção de um mundo rural rico, estável, permanente, imemorial, ancorado nas características da terra e da natureza, que, apesar dos pesares, nunca deixa de oferecer aos que trabalham um punhado de suas riquezas. Há, assim, um vínculo poderoso entre as relações sociais estabelecidas no sertão e as possibilidades oferecidas pela natureza, identificando umas com as outras de tal forma que as rupturas só poderiam ser pensadas em função da quebra de um ciclo natural, o que efetivamente

\footnotetext{
${ }^{8}$ José de Alencar, O Sertanejo, São Paulo, José Olympio, 1967 (1 ${ }^{a}$ ed. 1875). Este romance se insere no chamado ciclo regionalista do autor, que se completa com as obras $O$ Gaúcho (1870) e O Tronco do Ipêe (1871).
} 
ocorre em 1877, com a seca. Somente após esta data, portanto, o sertão aparece como "hostil" ou "inóspito", palco ressequido de uma vida de sofrimentos e resignação. Mas essa "quebra" não estava no horizonte de pensamento de Alencar. Ao contrário, sua atuação parlamentar nesse período, como deputado conservador, ficou marcada pela negação da seca e, portanto, pelo combate à liberação de verbas da rubrica "socorros públicos" para as províncias afetadas. A morte, contudo, o privou de ver os desdobramentos funestos da calamidade e, por conseqüiencia, a crise do mundo patriarcal que idealizava.

O que José do Patrocínio observa, portanto, é a decadência de um mundo rural aparentemente indestrutível, posto que ancorado na regularidade e na segurança da natureza, mas que se desagrega pela seca - o caos! Participa, assim, da construção de uma imagem de fragmentação e desagregação desse universo tradicional que se opera nas décadas finais do século XIX, configurando uma idéia geral de atraso e de incapacidade de superação dos obstáculos naturais, contribuindo para a formação de uma "ideologia da natureza perversa" que se desenvolve ao longo das décadas iniciais do século XX.

Uma visão nostálgica sobre um passado de fartura e segurança, identificada ao ponto de vista senhorial, passa, neste momento, a estigmatizar a natureza como fonte, simultaneamente, da abundância e da escassez. Este contraste entre um mundo rural idealizado, perfeito, e o retorno cíclico da crise é levado às últimas conseqüências pelo jornalista Mario Netto, para quem o Ceará "é um pomar encantado, um encantado viveiro, onde a vida animal e vegetal tem a pujança exhuberante dos trópicos"; a terra é "mãe fecunda e amorosa", que "distribue os thesouros de seu seio igualmente por todos os seus filhos" - "a vida sertaneja cearense é de um communismo perfeito"! À idealização da natureza corresponde a idealização das relações sociais. Os trabalhadores "exploram as parcelas de terrenos que lhes são arrendados, por conta própria e independentemente da retribuição dos serviços prestados aos fazendeiros". A repetição do fenômeno da seca, contudo, marca a vida do sertanejo, que é

(...) o Sisipho resignado, sabedor de seu destino cruento, attento ao rumor das tormentas próximas - a dôr deu lhe a faculdade da fortaleza ingenita, transmitida pela hereditariedade ancestral, consagrada no berço, bebida no seio das matronas robustas, mais tarde desenvolvida pelos exemplos viris dos pais.

A seca surge do nada, embora seja "esperada com estoicismo e temida com orgulho". Chega aos poucos, "com a hesitação de uma ladra”, e atinge 
igualmente a todos: é "a Fome que bate às portas dos pobres" e "é a miséria que despoja os cabedais dos ricos". ${ }^{9}$

O mundo sertanejo idealizado, de fartura e estabilidade, sem conflitos, se contrapõe ao tempo conflituoso e incerto da seca, da fome e da miséria, que chega sem aviso, posto que engendrada num mundo à parte, desconectada das relações sociais, "naturalizada". De O Sertanejo (1875), de José de Alencar, até Vidas Secas (1938), de Graciliano Ramos, uma transformação radical nos significados conferidos ao sertão torna-se perceptível, metamorfoseando a "secca do Norte" em "Nordeste seco" no imaginário político, literário e científico brasileiro.

Patrocínio tinha a missão de narrar essa seca para o público leitor da Corte e o fez de modo completo: enviou matérias para o Gazeta de Notícias, mandou fotografias para $O$ Besouro e escreveu um romance! ${ }^{10}$ Buscou estar presente em situações relevantes naquele momento dramático e avaliou criticamente as ações do governo, seguro que estava da inadequação das leis e do costume para a resolução de calamidades dessa natureza. Por meio de uma estratégia narrativa de grande impacto, procurou estimular nos leitores uma intensa indignação moral diante de uma tragédia sem precedentes, que ameaçava as bases de formação da nacionalidade e desafiava as inteligências de todas as áreas do conhecimento: era a "tragédia da vergonha nacional”, impregnada nos trabalhadores humilhados por salários irrisórios e rações estragadas, expressa pela multiplicação da prostituição e pela desagregação da família.

Contudo, parece ser na literatura que o investimento político de Patrocínio era mais acentuado, conforme a percepção predominante entre os intelectuais do Império. O romance Os Retirantes, resultado de todo esse acúmulo

\footnotetext{
${ }^{9}$ A Cidade, Sobral-CE, 15.08.1900.

${ }^{10}$ As fotos foram produzidas por J. Correa e o resultado pode ser interpretado como a primeira experiência de fotojornalismo no Brasil. Cf. Joaquim M. F. Andrade e Rosângela Logatto, "Imagens da seca de 1877-78 no Ceará: uma contribuição para o conhecimento das origens do fotojornalismo na imprensa brasileira", Anais da Biblioteca Nacional, Rio de Janeiro, v. 114, 1994, p. 71-83; Marta E. J. Barbosa, "Imprensa e Fotografia: imagens de pobreza no Ceará entre final do século XIX e início do século XX", Projeto História, São Paulo, no 24, 2002, p. 421-430; Alexandre Barbalho, "Corpos e Mentes Dilacerados: o grotesco nas imagens da seca de 1877", Trajetos, Fortaleza, v. 3, n 6, 2005, p. 139-150. As matérias eram publicadas na primeira página do Gazeta de Notícias, em coluna destinada a "Folhetim", sob o título geral de "Viagem ao Norte" e subtítulos variados.
} 
de experiências, seria publicado, primeiramente, em estilo de folhetim, no próprio Gazeta de Notícias, sendo concluído no ano seguinte (1879). ${ }^{11}$

A literatura - "inegavelmente a forma cultural por excelência do período e para a qual convergiam todos os esforços de redefinição dos valores sociais, avassalados pelo processo de transformações históricas" - arrebatou os intelectuais brasileiros de finais do século XIX em direção a uma batalha contra a fragmentação social que parecia resultar da crise política do Império. Os laços sociais precisavam ser reatados e o caminho estético encontrado foi o do realismo ou naturalismo, em que "a dimensão da história" passa a regular o tempo e a duração do romance. $\mathrm{O}$ "real" passa a ser o centro da narrativa literária, congregando a força do espírito e da razão contra o ímpeto fragmentário da imaginação. Ao mesmo tempo, e no mesmo movimento, a literatura já se havia tornado o elemento político fundamental por meio do qual as expectativas de intelectuais engajados na tentativa de reformar ou "civilizar" o país pareciam concretizar-se. Era no romance, principalmente, que os investimentos políticos dos intelectuais reformadores do segundo Império se encontravam sintetizados, concentrando toda a capacidade de convencimento público e toda a energia política de ampliação e divulgação das idéias modernas do liberalismo, do positivismo e do evolucionismo. Assim, pode-se afirmar que

\footnotetext{
${ }^{11}$ José do Patrocínio, Os Retirantes, 2 vs., São Paulo, Editora Três, 1973 (1ª ed. 1879). Em Fortaleza, Rodolfo Teófilo (1953-1932) - farmacêutico/jornalista/poeta/político/romancista/botânico - traça uma trajetória semelhante na análise da calamidade: faz anotações mensais, que publica posteriormente (1922) com o título de História da Secca do Ceará (em que reproduz algumas das mesmas fotos de J. Correa), e escreve um romance, A Fome (Rio de Janeiro, José Olympio; Fortaleza, Academia Cearense de Letras, 1979 - $1^{\text {a }}$ ed. 1890), que é, de fato, seu principal investimento intelectual e sua principal arma de combate político. As anotações, segundo ele mesmo, não passavam de observações gerais e testemunhos diretos a serem utilizados na composição dos personagens. $\mathrm{O}$ estilo realista ou naturalista faz com que os regimes de escrita (as anotações "reais" e as tramas ficcionais) se confundam. Interessante observar que Teófilo e Patrocínio passaram por Faculdades de Farmácia, respectivamente na Bahia e no Rio de Janeiro, um ramo considerado "menor" das atividades médicas, acessível aos mulatos e às camadas mais pobres que conseguiam meios de sobrevivência como estudantes. Teófilo, ao contrário de Patrocínio, praticou intensamente a profissão de farmacêutico, chegando a ser responsável pelo combate às epidemias (especialmente a varíola) na cidade, por meio da vacinação em massa da população, tendo construído um posto vacinogênico próprio e percorrido os mais afastados bairros em busca de doentes ou pessoas desprotegidas, utilizando métodos pouco convencionais, porém eficazes. Cf. Rodolpho Theophilo, Varíola e Vacinação no Ceará, Fortaleza, Officinas do Jornal do Ceará, 1904; Lira Neto, O Poder e a Peste - A Vida de Rodolfo Teófilo, Fortaleza, Edições Demócrito Rocha, 1999.
} 
"o prestígio ímpar da literatura a transformava num instrumento particularmente eficiente de propaganda intelectual". ${ }^{12}$

Mais do que na "história" ou no jornalismo - visto como tábua de salvação dos intelectuais deslocados dos centros do poder pelo projeto conservador da República, que sairia vencedor depois de 1889 - era na literatura que os investimentos políticos e intelectuais haveriam de se concentrar. Neste sentido, não se tratava tão-somente de narrar, mas de envolver o "público" leitor, por meio de estratégias "realistas" e impactantes, em uma rede de significados que pudesse reafirmar certos valores morais e referências éticas, bases para um conjunto de hábitos e comportamentos "civilizados", de acordo com o sentido dispensado a esta noção integrativa no final do século XIX. A própria exposição do "real", sem maquiagens retóricas e com riqueza de detalhes mórbidos, produziria o efeito pretendido pelo escritor.

Os Retirantes tematiza o processo de retirada, em que as famílias sertanejas, esgotadas todas as fontes de recursos, próprios ou distribuídos pela caridade ou pelo governo, ${ }^{13}$ deixam suas pequenas cidades ou fazendas para procurar o apoio ou a ajuda do governo na capital da província, Fortaleza - uma cidade de cerca de 25 mil habitantes em 1877, mas onde foram contabilizados pelo menos 114 mil retirantes famintos e doentes em 1878. Era um trajeto novo, engendrado em meio às transformações socioeconômicas que se desenrolavam nos anos posteriores a 1850. As rotas tradicionais, em direção às serras, às terras úmidas e às praias, haviam-se fechado, entre outras razões, pela ampliação da agricultura comercial do algodão, exigindo dos camponeses pobres um aprendizado novo sobre as relações de poder em tempos de escassez, quando

\footnotetext{
${ }^{12}$ Nicolau Sevcenko, Literatura como Missão: Tensões sociais e criação cultural na Primeira República, $3^{\text {a }}$ ed., São Paulo, Brasiliense, 1989, p. 226-227. É interessante anotar que o conservador José de Alencar também apostava "na literatura como instrumento eficaz de intervenção sobre os rumos da sociedade”. Sílvia C. M. Souza, “Ao correr da pena': uma leitura dos folhetins de José de Alencar", S. Chalhoub e L. A. Miranda (orgs.), A História Contada: capitulos de história social da literatura no Brasil, Rio de Janeiro, Nova Fronteira, 1998, p. 124.

${ }^{13}$ Patrocínio critica a caridade exercida como favor pelo governo por meio da distribuição de esmolas. Defendeu a posição do Conselheiro Aguiar, que presidiu a província por alguns meses, para quem, segundo o jornalista, era papel do Estado desenvolver uma política de socorros públicos que permitisse, ao mesmo tempo, "economizar os dinheiros públicos" e "prestar ao povo o socorro constitucional". Ele conclui: "A esmola era o que se distribuía anteriormente, agora distribuía-se outra coisa, o socorro. No primeiro caso funcionava a caridade do estado, no segundo o estado cumpria um dever". Gazeta de Notícias, Rio de Janeiro, 12.09.1878.
} 
o Estado passa a assumir muitas funções, antes concentradas nas mãos dos coronéis, dos senhores de terras e das gentes. ${ }^{14}$

Por meio das conturbadas trajetórias dos personagens Eulália e Irena, amigas pertencentes a famílias prestigiadas na localidade de B.V., respectivamente os Queiroz e os Monte, Patrocínio procura enfocar aspectos que considera relevantes na análise do processo que se desenrolava ante seus olhos. A sina de Eulália parece resumir toda a tragédia da seca: filha mais velha do professor público Francisco de Queiroz, educada na mais rígida formação moral sertaneja, religiosa e casta, vê seu mundo estável e seguro desabar após a morte do pai; sem recursos de espécie alguma, deixa-se seduzir pelo vigário Paula (a figura mais corrupta do romance, concentrando todo o anticlericalismo de Patrocínio) e muda-se com as irmãs menores e a tia velha para Fortaleza, onde, para garantir a integridade moral da família, prostitui-se e protagoniza uma morte desonrosa, no meio da rua principal da cidade, no momento mesmo do casamento de sua melhor amiga. Esta, Irena, empobrece mais rapidamente - o pai, o "velho criador" Rogério Monte, perde subitamente suas referências socioeconômicas, baseadas na terra, nos escravos, no gado e na produção do algodão - e passa toda a trama acompanhando o pai, já doente e cego, na busca do noivo prometido (ironicamente, um membro da família Feitosa), ${ }^{15}$ é recompensada, ao final, com um casamento abastado, apesar da morte do pai e de sua amiga Eulália.

Irena, não obstante a mais intensa penúria, jamais perde a referência masculina da família - ao pai, que, mesmo doente, garante a defesa dos valores morais da filha virgem, sucede o amado Feitosa, que lhe garante o sustento e uma nova família como referência social. A constante presença masculina, mesmo precária, lhe permite defender-se dos assédios dos aproveitadores.

Eulália, ao contrário, desloca-se pelo romance sem encontrar pontos de sustentação, à procura de meios para evitar a decadência das irmãs e a desmoralização da tia querida. Sem referências masculinas para defender sua honra, deixa-se prostituir e, sempre angustiadamente, consegue, com sua degradação, impedir a degradação do restante da família. A seca aparece-lhe como uma estrutura exterior e intransponível, um destino irrecusável, uma

\footnotetext{
${ }^{14}$ Frederico de Castro Neves, "A Lei de Terras e a Lei da Vida: transformações no mundo rural do Ceará no século XIX”, Estudos de História, Franca-SP, v. 8, n 2, p. 37-58, 2001.

${ }^{15}$ Os Monte e os Feitosa protagonizaram as mais violentas lutas de famílias no interior do Ceará, desde o início do século XVIII. Cf. Billy J. Chandler, Os Feitosas e o Sertão dos Inhamuns, Rio de Janeiro, Civilização Brasileira, 1980.
} 
barreira invisível e poderosa, que nem mesmo a força da moral sertaneja consegue sobrepujar; contudo, até o fim permanece fiel aos valores da honra pessoal e do trabalho como fundamento ético da vida, heranças da formação moral das famílias sertanejas com algumas posses.

O romance centra-se na vida de famílias abastadas e seus dramas, no interior de um processo que se procura apresentar como universal: a seca afeta a todos $!^{16}$ Os camponeses pobres - na verdade, os grandes protagonistas da miséria e da fome - aparecem como um cenário vivo de degradação e morte. Sombras sem nome nem sobrenome, que se movimentam continuamente em torno dos personagens centrais. Sem o cultivo ilustrado de valores enraizados no cristianismo e na tradição, os trabalhadores, como "exercito sorprehendido", rendem-se às circunstâncias, humilhando-se na esmola, degradando-se na prostituição e vivendo às custas do Estado. Os valores de um mundo rural idealizado caracterizavam uma nova figura literária no momento de sua crise, o cearense, que, "laborioso e altivo", "tinha pela honra o culto fanático dos fakirs aos seus ídolos"; ao mesmo tempo, o "trabalho era a sua corôa de gloria" ${ }^{17} \mathrm{O}$ cearense de Patrocínio assemelha-se ao sertanejo de Alencar, e sua rápida decadência acompanhava a decadência econômica e social de todo um universo tradicional, com seus valores e sua abundância.

A rapidez dessa decadência está ligada, de um lado, à desagregação da família camponesa, obrigada a circular pelas estradas destruídas e perigosas, por várias localidades, antes de dirigir-se a Fortaleza. Nesses sinuosos trajetos, narrados em parte no romance (na medida em que se cruzam com a trajetória dos Queiroz ou dos Monte), perdia-se a altivez e a proximidade cada vez maior da fome anestesiava os mecanismos de defesa da honra. Mortes e desencontros, nestes caminhos extremamente longos e secos (lembre-se não só da qualidade das estradas no Ceará do século XIX, mas também da distância que esses retirantes eram obrigados a percorrer), desfaziam a unidade familiar, por vezes pela partida ou morte de seu chefe, por vezes pela ação desmoralizadora de elementos depravados de camadas mais abastadas, que rondavam permanentemente a desgraça dos pobres, especialmente das pobres donzelas. Por outro lado, os camponeses são ignorantes e rudes, incapazes de

\footnotetext{
${ }^{16}$ Em A Fome, de Rodolfo Teófilo, a trama acompanha a trajetória do coronel Manuel de Freitas e sua família. Neste caso, mesmo arruinado, o orgulhoso líder sertanejo não aceita a esmola governamental, recebendo apoio de um comissário de distrito, como ajuda de caráter estritamente pessoal. A permanência da unidade familiar garante à filha Carolina a defesa da honra contra os assédios do mesmo comissário Arruda.

${ }^{17}$ Gazeta de Notícias, Rio de Janeiro, 22.08.1878.
} 
cultivar racional e conscientemente os valores morais da família e da ordem senhorial. Sem a ferramenta da cultura, da leitura e da escrita, Patrocínio não vislumbra possibilidades de segurança para os valores morais que tanto preza, implodidos pela "tragédia da vergonha nacional", sintetizada na corrupção moral e na ineficiência do Estado. Nesse momento, sem o apoio da cultura letrada, o pânico predomina sobre a razão e "a superstição abriu logo as longas asas de corvo e pairou sobre os espíritos acovardados". ${ }^{18}$ A proximidade da fome, portanto, acentuava o peso dos mecanismos naturais e interiores de defesa da vida, sobrepujando as amarras exteriores da cultura. Desprovidos de defesas culturais e expostos à fome biológica, os camponeses distanciam-se da sociedade civilizada e animalizam-se, desqualificando-se como sujeitos sociais e perdendo a própria identidade política. Sem rosto, passeiam pelo romance como uma massa de homens e mulheres geográfica e imaginariamente deslocados, desgraçados pelo destino inevitável. São criaturas indefesas, sem as referências morais dos proprietários de terras, os quais lhes fornecem não somente as possibilidades econômicas de acesso restrito às terras, mas, principalmente, os limites rígidos da conformação social.

O controle senhorial, portanto, possui um efeito agregador fundamental para a estabilidade da sociedade sertaneja, segundo a ótica conservadora. Sob o domínio dos proprietários brancos, a cultura rural permanece coesa e forte, base de sustentação do edifício nacional. A seca, ao desfazer os laços que unem senhores e camponeses, pela destruição da produção e pela migração generalizada, enfraquece o controle que os senhores de terras exercem sobre toda a sociedade, abrindo espaço para a desagregação social e moral que Patrocínio e outros tantos denunciam. Assim, o tema da seca está intrinsecamente associado ao tema da decadência dos senhores rurais e sua incapacidade de manter o controle sobre as gentes em retirada. Por isto, a degradação a que ele sempre se refere é de natureza eminentemente moral, relativa ao declínio do controle senhorial sobre as consciências.

Sem os limites advindos da presença direta dos proprietários rurais, os camponeses progressivamente desvencilham-se das rígidas amarras da moralidade sertaneja. Patrocínio observa esta progressiva e dolorosa decadência em que, antes de chegar ao "extremo aviltante" do roubo, o cearense "não recua diante dos maiores sacrifícios". Destruídas as possibilidades de produzir a subsistência por conta própria, os retirantes sujeitam-se ao "trabalho pelo

${ }^{18}$ José do Patrocínio, Os Retirantes, op. cit., v. 2, p. 24. 
salário de cento e vinte réis diários, e até unicamente pela comida"; vendem "tudo o que possuem", inclusive terras, jóias de família, os cabelos das mulheres - "os bellos cabelos negros das cearenses" - e até mesmo "a rede em que dormiam". Por fim, "os próprios esposos, pais e irmãos propõem a transacção ignominiosa e depois vão mastigar em silêncio o pão arrancado ao sacrifício dos sentimentos mais respeitáveis e á infâmia dos abastados". Conclui que "a maioria dos retirantes, ainda semi-selvagem, prefere mercadejar com a honra da família a commeter um furto". Todavia, o respeito à propriedade privada não é apenas um valor educado na moralidade sertaneja, mas uma luta cotidiana em que qualquer transgressão é vista como uma ameaça à ordem senhorial e punida com o maior rigor. O jornalista carioca observa, a este respeito, que "o furto de algumas cannas e laranjas verdes tem sido arbitrariamente punido com a morte". Muitas vezes, após um "processo summario", o próprio proprietário termina infligindo aos acusados "o castigo de algumas dúzias de palmatórias e chicotadas ou então a pena de ter a cabeça raspada em cruz". A justiça sertaneja, baseada quase unicamente no discernimento dos senhores de terras, aplica-se com a mesma violência dos bandos de jagunços que percorrem as áreas semi-abandonadas, espalhando o terror e o medo. Esta última pena parece a Patrocínio como a "mais severa", pois condena o desgraçado a uma trajetória de desprezo, "sem despertar a mínima compaixão". A cabeça raspada é seu "passaporte amarello de João Valjean”, com o qual "supplicará debalde um punhado de farinha" e "procurará em vão trabalho", morrendo enfim na mais completa penúria, desprezado pelos semelhantes. ${ }^{19}$

Todavia, o trabalho disponível para esses homens do campo, nesse momento extraordinário, era igualmente degradante. Embora fossem trabalhadores livres, estavam sujeitos às maiores humilhações no mundo do trabalho - se os socorros públicos pleiteados por Patrocínio e outros intelectuais e políticos deveriam ter o efeito de formar trabalhadores ao invés de fomentar a ociosidade, o tratamento dado por comissários e administradores condizia com a mentalidade escravocrata de desprezo ao trabalho manual e de exigência de total submissão do trabalhador: "reina extraordinariamente o preconceito das côres e raças", observa, indignado. O Presidente da Província, reconhece Patrocínio, procura organizar o sistema de pagamentos, instituindo uma série de instruções sobre os procedimentos a serem adotados pelos responsáveis pelo pagamento de salários e rações. Contudo, "taes medidas não passaram

${ }^{19}$ Gazeta de Notícias, Rio de Janeiro, 15.08.1878. 
da boa vontade do administrador e dos typos do periódico official": satisfeito com as instruções baixadas, o Conselheiro José Júlio de Albuquerque Barros "não attendeu para o malogro das suas instruções", permitindo o desenvolvimento da "insubordinação, anarchia e desprestígio", e "limitou-se a calçar fleugmaticamente as suas luvas e ouvir musica, ás quintas e domingos, da janela de seu palácio", enquanto os conflitos nas pagadorias dos retirantes se agravavam cada vez mais. ${ }^{20}$

O trabalho, portanto, não regenerava! A "classe dos trabalhadores", embora composta de homens "mais robustos", desfilava pelas ruas em direção aos locais de trabalho como se fosse para o abatedouro: o "passo arrastado" e o olhar baixo "faziam perceber a sua humilhação". Patrocínio não via "desenhar-se-lhes no semblante o orgulho de quem pelo próprio esforço conseguiu arrancar á adversidade meios de subsistência”, mas percebia que a remuneração dos serviços, além de um sistema de trabalho extenuante e despótico, não era suficiente para recuperar, no retirante, os valores positivos do trabalho. Vivendo em um mundo tradicional, em que o empenho no trabalho é legitimado e garantido pela presença constante - despótica e violenta - dos senhores de terras, os retirantes tendiam a ver declinado o gosto e a inclinação natural pelo trabalho ao mesmo tempo em que declinavam as possibilidades de subsistência; os serviços de socorros não eram capazes de restituir esse vínculo, nem de constituir um novo, baseado nas idéias de "direitos" e "deveres". Os trabalhadores, assim, apareciam para Patrocínio vestidos "pelo mesmo figurino - o da vergonha nacional". ${ }^{21}$

Desse modo, Patrocínio, tematiza o processo generalizado de degradação moral a que todos, de maneiras diferentes, estavam submetidos como resultado da seca. Os senhores, incapazes de manter o controle social e político sobre "seus" dependentes, se enfraquecem social e politicamente; os camponeses, vagando sem senhores pelas estradas ressequidas, degradam-se na luta desesperada pela vida. Chama a atenção, especialmente, para o crescimento assustador da prostituição, principalmente promovida pelos próprios familiares, como forma de trocar a honra das mulheres por comida, abrigo ou acesso aos benefícios dos socorros públicos. É no contexto de decomposição

\footnotetext{
${ }^{20}$ Gazeta de Notícias, Rio de Janeiro, 03.08.1878. Neste mesmo mês de agosto, por exemplo, cerca de 6 mil retirantes amotinados atiraram pedras contra os soldados da polícia e da cavalaria, resultando em um confronto generalizado nas praças centrais da cidade. Cf. Frederico de Castro Neves, "Estranhos na Belle Époque: a multidão como sujeito político", Trajetos, Fortaleza, v. 3, no 6, p. 123-124, 2005.

${ }^{21}$ Gazeta de Notícias, Rio de Janeiro, 23.07.1878.
} 
de um mundo rural de abundância material e cultural que este processo ocorre, arrastando os personagens, na maioria das vezes, para um fim trágico que não podem evitar nem sequer compreender. Como o peso de um destino inevitável, os personagens deslocam-se pela trama à procura de saídas (que nunca encontram) e de segurança (sempre precária), idealizando uma "idade do ouro", figurada em um passado longínquo, quando reinavam a abundância e a paz (ao contrário da experiência "real" da vida sertaneja, marcada muito mais pela carência permanente e a violência constante). Segundo ele, "conservavamse límpidas, em todas as memórias, as recordações dos tempos prósperos", 22 levando ao desespero os chefes de família, incapazes de evitar, ou meramente compreender, o processo em que estavam inseridos.

No entanto, os dias de glória do sertão algodoeiro-pecuário não aparecem explicitamente na narrativa de Os Retirantes. Patrocínio, ao contrário de muitos escritores do período, não procura descrever, logo no início do livro, o ambiente geográfico em que a trama se desenrolará. Não só a fartura de tempos passados, mas também a carência do tempo presente são descritas retrospectivamente na trama e na ação dos personagens, definindo seus movimentos e "cenarizando" suas decisões. O universo sertanejo idealizado por Alencar está presente, por contraste, nas descrições minuciosas da desgraça e no contato permanente de personagens íntegros (como Eulália, apesar de seu destino ingrato) e outros, inteiramente degradados (em especial o vigário Paula, para quem a seca fez tão-somente acentuar a falta de caráter) com um momento extraordinário da vida nacional, quando os valores cristãos básicos de socialização por meio da família e da educação dos filhos estão sob ameaça iminente. Episodicamente, contornos de relações sadias e moralizadas emergiam de um mar de desolação moral: nestes momentos, a referência era a "fraternidade dos tempos prósperos", quando "o nobre coração cearense revelava-se inteiro em tamanha espontaneidade". ${ }^{23}$

Os traços de caráter do sertanejo, definidos por Alencar - honra pessoal, altivez, gosto pelo trabalho, obediência, lealdade, valorização da terra e da família - delimitam as características dos personagens de Patrocínio, determinando o horizonte de possibilidades em que formulam suas ações e seus pensamentos. Os Retirantes e $O$ Sertanejo representam, portanto, os dois lados de uma mesma moeda de idealização do mundo senhorial sertanejo, vistos sob a ótica conservadora de dois escritores geniais.

${ }^{22}$ Gazeta de Notícias, Rio de Janeiro, 22.08.1878.

${ }^{23}$ José do Patrocínio, Os Retirantes, op. cit., v. 2, p.87. 